Provided for non-commercial research and education use. Not for reproduction, distribution or commercial use.

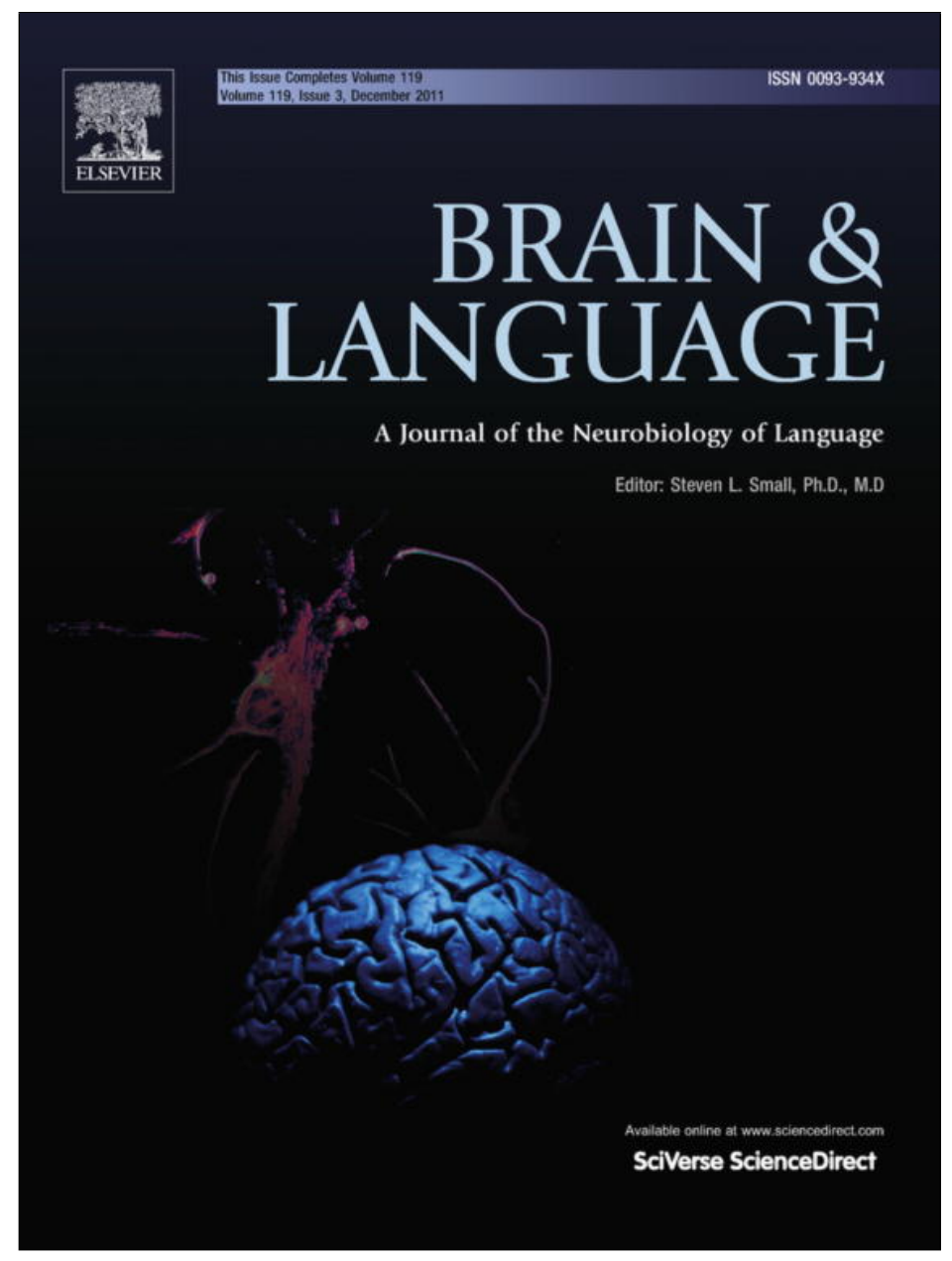

This article appeared in a journal published by Elsevier. The attached copy is furnished to the author for internal non-commercial research and education use, including for instruction at the authors institution and sharing with colleagues.

Other uses, including reproduction and distribution, or selling or licensing copies, or posting to personal, institutional or third party websites are prohibited.

In most cases authors are permitted to post their version of the article (e.g. in Word or Tex form) to their personal website or institutional repository. Authors requiring further information regarding Elsevier's archiving and manuscript policies are encouraged to visit:

http://www.elsevier.com/copyright 
Short Communication

\title{
BOLD response to motion verbs in left posterior middle temporal gyrus during story comprehension
}

\author{
Mikkel Wallentin a,b,*, Andreas Højlund Nielsen ${ }^{\mathrm{a}, \mathrm{c}}$, Peter Vuust ${ }^{\mathrm{a}, \mathrm{d}}$, Anders Dohn ${ }^{\mathrm{a}, \mathrm{d}}$, Andreas Roepstorff ${ }^{\mathrm{a}, \mathrm{c}}$, \\ Torben Ellegaard Lund ${ }^{\mathrm{a}}$ \\ ${ }^{a}$ Center of Functionally Integrative Neuroscience, Aarhus University Hospital, Nørrebrogade, 8000 Aarhus C, Denmark \\ ${ }^{\mathrm{b}}$ Center for Semiotics, Aarhus University, Denmark \\ ${ }^{\mathrm{c}}$ Department of Anthropology, Archaeology and Linguistics, Aarhus University, Denmark \\ ${ }^{\mathrm{d}}$ Royal Academy of Music, Aarhus/Aalborg, Denmark
}

\section{A R T I C L E I N F O}

\section{Article history:}

Accepted 24 April 2011

Available online 25 May 2011

\section{Keywords:}

fMRI

Language comprehension

Narrative

Motion verbs

Simulation framework

Left posterior middle temporal gyrus

\begin{abstract}
A B S T R A C T
A primary focus within neuroimaging research on language comprehension is on the distribution of semantic knowledge in the brain. Studies have shown that the left posterior middle temporal gyrus (LPMT), a region just anterior to area MT/V5, is important for the processing of complex action knowledge. It has also been found that motion verbs cause activation in LPMT. In this experiment we investigated whether this effect could be replicated in a setting resembling real life language comprehension, i.e. without any overt behavioral task during passive listening to a story. During fMRI participants listened to a recording of the story "The Ugly Duckling". We incorporated a nuisance elimination regression approach for factoring out known nuisance variables both in terms of physiological noise, sound intensity, linguistic variables and emotional content. Compared to the remaining text, clauses containing motion verbs were accompanied by a robust activation of LPMT with no other significant effects, consistent with the hypothesis that this brain region is important for processing motion knowledge, even during naturalistic language comprehension conditions.
\end{abstract}

(c) 2011 Elsevier Inc. All rights reserved.

\section{Introduction}

A central question for neuroimaging research on language comprehension processes relates to how linguistic meaning is distributed across the brain. The embodied cognition/simulation framework maintains that semantics to some extent is grounded in sensorimotor experiences and that cognitive processes underlying sensorimotor function are engaged during online conceptual processing so as to re-enact modality-specific patterns of activity that are normally evoked during perception and action (Barsalou, 2008; Barsalou, Simmons, Barbey, \& Wilson, 2003; Kemmerer, 2010; Meteyard, Cuadrado, Bahrami, \& Vigliocco, 2010; Pulvermüller, 2005). A growing body of evidence has been found in support of this claim, both from behavioral science (Meteyard, Bahrami, \& Vigliocco, 2007; Richardson \& Matlock, 2007; Zwaan, Madden, Yaxley, \& Aveyard, 2004; Zwaan, Stanfield, \& Yaxley, 2002) and from neuroimaging (Hauk, Johnsrude, \& Pulvermüller, 2004; Kemmerer, Castillo, Talavage, Patterson, \& Wiley, 2008;

\footnotetext{
* Corresponding author at: Center of Functionally Integrative Neuroscience, Aarhus University Hospital, Nørrebrogade, 8000 Aarhus C, Denmark. Fax: +45 89494400.

E-mail address: mikkel@cfin.au.dk (M. Wallentin).
}

Wallentin, Weed, Østergaard, Mouridsen, \& Roepstorff, 2008; Wallentin, Østergaard, Lund, Østergaard, \& Roepstorff, 2005). The relationship between sensorimotor processing of motion and its linguistic counterpart is a key example of this. Area MT/V5 of the posterior temporal lobe is known to be involved in the processing of visual motion (Dumoulin et al., 2000; Zeki et al., 1991). The left posterior middle temporal gyrus (LPMT), a region just anterior to area MT/V5, has been found to be important for the processing of complex action knowledge (Kourtzi \& Kanwisher, 2000; Phillips, Noppeney, Humphreys, \& Price, 2002; Ruby \& Decety, 2001). Single word studies comparing motion verbs with object words (Kable, Lease-Spellmeyer, \& Chatterjee, 2002) or nonmotion verbs (Noppeney, Josephs, Kiebel, Friston, \& Price, 2005; Revill, Aslin, Tanenhaus, \& Bavelier, 2008) found that this region was also involved in linguistic processing, as predicted by the simulation framework. However, others have found that the region responds more to verbs than to nouns in general and have suggested that the region is involved in a more abstract processing of event concepts or verb grammar (Bedny, Caramazza, Grossman, Pascual-Leone, \& Saxe, 2008). This interpretation is countered by studies directly comparing whole sentences containing action/motion verbs with sentences depicting stationary content. These have also found increased activation in LPMT (Rueschemeyer, Glenberg, 


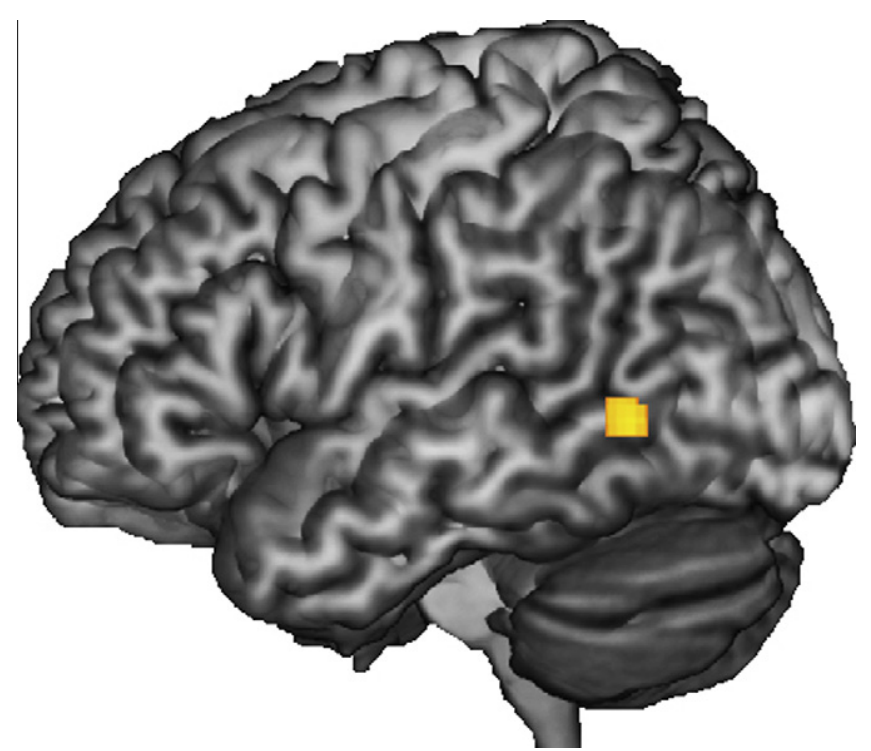

Fig. 1. Significant BOLD response for motion verbs were found only in the left posterior middle temporal gyrus [LPMT], $P<0.05$ FWE corrected.

Kaschak, Mueller, \& Friederici, 2010; Wallentin, Lund, Østergaard, Østergaard, \& Roepstorff, 2005), suggesting that the region is more involved in action verb processing.

However, for any of these findings to be truly valid, they have to be replicated also in an ecologically valid linguistic context (Small \& Nusbaum, 2004). But conducting and analyzing experiments with more naturalistic stimuli, such as real stories, is complicated by the many factors possibly co-varying within each narrative. Only recently have researchers therefore begun to use stories to investigate the neural processing of complex linguistic representations (Crinion, Lambon-Ralph, Warburton, Howard, \& Wise, 2003; Wilson, Molnar-Szakacs, \& Iacoboni, 2007; Xu, Kemeny, Park, Frattali, \& Braun, 2005; Yarkoni, Speer, \& Zacks, 2008), such as syntax (Brennan et al., in press), event boundaries (Speer, Zacks, \& Reynolds, 2007), representational changes in space/time/characters/goals or objects (Speer, Reynolds, Swallow, \& Zacks, 2009) and motion representation (Deen \& McCarthy, 2010). In the latter experiment participants read brief stories that described a person and ended with the description of a biological motion event or a decision made by the person. Effects of motion descriptions were again found in the posterior part of the temporal lobe. The authors locate the brain activity to the superior temporal sulcus, bilaterally, but the coordinates are very similar to those reported as LPMT in the single word and sentence studies [MNI: $-60,-60,2]$.

In the present experiment we continued this line of work by investigating if clauses containing motion verbs embedded in other complex linguistic content would be accompanied by increased BOLD activation in LPMT during passive listening to a real story. The current experiment differed from the Deen and McCarthy study by using auditory stimuli rather than reading, by using a long uninterrupted narrative rather than several shorter and by modeling each motion verb clause as an event rather than analyzing over a whole paragraph. It further differed by adopting a conservative nuisance variable regression strategy (Lund, Madsen, Sidaros, Luo, \& Nichols, 2006) for control of potential confounds in the stimuli. This implied adding regressors to the analysis modeling both physiological noise (cardiac pulsation and respiration) and head movement, but also sound intensity variation, word frequencies, word cooccurrences and emotional effects. Only effects over and beyond these other modeled effects would be picked up by the motion verb regressor with this approach. Furthermore, since the motion verb effects were interleaved with other linguistic effects this meant that the analysis would only pick up on signal which had an activity profile different from what would have been left unmodeled in the analysis, thus effectively canceling out other linguistic effects.

The Danish fairy tale "The Ugly Duckling" (Danish: "Den grimme ælling”) by Hans Christian Andersen (1805-1875) was used as narrative material. The story is considered a Danish Classic and has been translated into many languages, including English (e.g. see http://www.andersen.sdu.dk/vaerk/hersholt/TheUglyDuckling_e.html). This story contains paragraphs with a lot of explicit motion description interleaved with passages containing dialog and descriptions, making it a highly suitable stimulus for the present investigation.

Participants listened to a recording of the narrative while lying in a 3T MR-scanner. Immediately before and after scanning a multiple choice test probed their knowledge of the text in order to secure attention to the story. Two independent raters tagged the text for presence of motion verbs. Time stamps for the tagged clauses were used to make a regressor for statistical analysis of the BOLD fMRI data (for a detailed descriptions of methods see Section 4 and Wallentin et al., submitted for publication).

\section{Results}

Two significant blobs were found at $P<0.05$ (FWE corrected for multiple comparisons), both in the LPMT (MNI peaks: $[-60,-62$, $0], t(23)=7.29$ and $[-48,-58,0], t(23)=7.41)$. No other activations reached significance (see Fig. 1).

\section{Discussion}

By definition, natural language stimuli, such as stories make up a less well-controlled experiment than single word studies. Nevertheless, it is important to show that the processes observed under more strict control are also present under conditions resembling real life. In this study we have attempted to study language comprehension as it happens when participants are given no task to solve other than following a story. Contrary to most cognitive experiments we thereby avoid the danger of induction by instruction, i.e. the danger of the experimental setup in itself creating the effect that it intends to study (Roepstorff \& Frith, 2004). The price for this is a lack of control. To counter some of the consequences of this lack we have chosen, we believe, the most conservative data analysis procedure available in the literature. We have measured and factored out most known nuisance variables, such as cardiac pulsation, respiration, head movement and sound level variation prior to analysis and we have used the most conservative correction for multiple corrections available in SPM. And although the analysis does not contain a direct contrast between the motion clauses and control clauses, indirectly the baseline is the rest of the text, effectively canceling out all other linguistic effects. Therefore the robust activation in LPMT supports the hypothesis that this brain region is important for processing motion knowledge, also when this is transmitted through naturalistic language. This result, together with those of Deen and McCarthy (2010) thereby directly contradicts findings suggesting that this region is involved in event knowledge in general or with verb grammar in particular as suggested by Bedny et al. (2008). These findings are also corroborated by data from brain-damaged patients where LPMT lesions along with frontal regions have been found to cause impairments on a number of tasks related to conceptual knowledge of actions (Kemmerer, Rudrauf, Manzel, \& Tranel, in press). However, this does not put all controversies related to the embodiment of action verbs to an end. A crucial debate within the embodiment literature relates to how literal one should take 
the hypothesis. A distinction between a strong and a weak embodiment hypothesis has been suggested (Kemmerer, 2005; Meteyard et al., 2010). The strongest embodiment stance would claim that involvement of sensorimotor systems in processing of language is necessary, automatic and pervasive, whereas weaker notions of the embodiment hypothesis would argue that involvement of sensorimotor systems in language processing may be one out of several routes for comprehension, and thus may not always be necessary, but rather involved on a strategic basis, voluntarily or not, e.g. when language is used to refer directly to sensorimotor experiences or when full-fledged imaginary representations are beneficial, such as they might be while listening to a story. In terms of localization of processing, a strong claim would be that the same regions are involved in sensorimotor and linguistic processing whereas a weaker account would suggest that overlapping or contiguous regions might be responsible for the different processes (Meteyard et al., 2010). The fact that the present findings are located in LPMT, located anterior to V5/ MT, seems to support a weaker hypothesis where an anterior shift in localization might mark a more abstract level of representation (Chatterjee, 2010; Thompson-Schill, 2003). But this conclusion may be premature. We did not use a functional localizer in the present experiment. Therefore we cannot be absolutely sure were V5/MT is located in the present sample. Further, area V5/MT is a region involved in the processing of visual motion, but motion itself is of course, a multimodal experience and regions of overlap between visual and non-visual processing of motion may not be located in V5/MT, in fact many studies suggest that they are not (Bremmer et al., 2001; Krumbholz et al., 2005; Smith, Saberi, \& Hickok, 2007; Warren, Zielinski, Green, Rauschecker, \& Griffiths, 2002), rather the majority of studies seem to suggest that cortical processing of auditory motion is located in the planum temporale which would place LPMT right in the middle between the visual and auditory motion processing regions. It is therefore not yet clear whether LPMT is used for representing motion that is abstract in a linguistic sense or simply abstract in the sense of being multimodal. Indeed, this distinction may not even be valid given that studies seem to suggest that language plays a modulating role in the development of sensorimotor categories in humans (e.g. see Tylén, Weed, Wallentin, Roepstorff, \& Frith, 2010 for a review). Abstraction may also be a consequence of including several different verbs under the heading "motion verbs" (see Table 1). LPMT may thus be the region of overlap between these different kinds of motion verbs, whereas more specific verbs may yield activation in regions of the brain supporting more specific sensorimotor functions, such as V5/MT and/or motor cortex (Hauk et al., 2004; Kemmerer et al., 2008). However, the limited frequency of such highly specific motion verbs in the current story does not facilitate a more detailed semantic analysis. But this does not take away the significance of the finding that at the level of abstraction studied in the present experiment, LPMT is activated by motion verb clauses, even under naturalistic language comprehension conditions.

Table 1

Most frequent verbs.

\begin{tabular}{lc}
\hline Verbs & Frequency \\
\hline KOMME [come] & 12 \\
GÅ [walk/go] & 8 \\
FLYVE [fly] & 7 \\
SLÅ [hit] & 5 \\
LØBE [run] & 4 \\
FARE [race/rush] & 3 \\
SVØMME [swim] & 3 \\
\hline
\end{tabular}

\section{Methods and materials}

\subsection{Participants}

Twenty-six participants (17/9 male/female; median age: 25 years, range: $20-47$ years) were scanned. Permission for the study was obtained from the local ethics committee (Region Midtjylland, Denmark) and written informed consent was obtained from each participant. Each received a 100 DKK payment per hour for participation. Gender was not considered important for analyses (Wallentin, 2009). All participants had Danish as their primary language. All participants were right-handed as measured by the Edinburgh Inventory (Oldfield, 1971; score range 80-100). Data from one participant was lost and one was excluded due to chance behavior on the post scanning memory test.

\subsection{Materials}

A professional recording of The Ugly Duckling was used. This recording included the first 3115 words of the text, leaving out the two last paragraphs. These paragraphs were not considered essential for the story. The recording lasted $21 \mathrm{~min}$. Sound was played in mono (sample frequency: $22,050 \mathrm{~Hz}$ ) through pneumatic headphones from Avotec (Stuart, FL USA).

Immediately before and after the story, participants answered a multiple-choice test probing their detailed memory of The Ugly Duckling. Participants read 20 sentences from the narrative and chose for each between five possible completions of the sentence.

All participants except one (who was excluded) had postscanning scores significantly above chance level (median score 17; range 14-20) and all participants improved from pre- to post-scanning.

There was no overt behavioral task linked to story comprehension during scanning. To ensure attention to the sound participants were instructed that they had to press a button when they heard a voice other than the one narrating the story utter the word "nu" ["now"]. This happened four times throughout the scan. All participants complied with this demand, suggesting that they were attending to the sound. All participants reported during debriefing that they had been able to hear the story through the scanner noise without any problems.

\subsection{Narrative analysis}

With an approach similar to that reported by Zacks, Speer, and Reynolds (2009), two independent raters (first and second authors of this article) tagged each clause in the story for whether it contained a finite motion verb or not. In this procedure we followed Anderson (2007) in his definition of finiteness. Both raters had knowledge of the hypothesis prior to tagging. Motion verbs were defined as those that described physical motion either selfpropelled or caused by a physical force (e.g. the wind) acting upon an object. Verbs denoting speech were not regarded as motion verbs, whereas motion verbs describing what is known as "fictive" motion (Talmy, 2000), e.g. "the tree branches stretched beyond the reeds", were also included as these have previously been found to yield comparable neural responses to those describing concrete motion events (Wallentin et al., 2005). Inter-rater agreement was high (Pearson's $r=0.84$ ) and discrepancies were solved by discussion.

Throughout the 3115 words long story 92 motion verbs were identified (seven depicting "fictive" motion), yielding 68 motion events (single or contiguous strings of motion verb clauses) consisting of a total of 765 words. Six verbs were held in the present 
tense, four were in imperative mood and the rest were held in past tense. The most frequent verbs can be seen from Table 1 .

\subsection{Data acquisition}

A 3T General Electrics Medical Systems (Milwaukee, WI, USA) MR system with an eight-channel Invivo (invivo.com) head coil was used to acquire both $T_{2}^{*}$-weighted gradient echo, echo-planar images (EPI) with Blood Oxygenation Level-Dependent (BOLD) contrast and $T_{1}$-weighted anatomical images. $570 \mathrm{EPI}$ volumes were acquired per participant, not including the first five volumes that were discarded to allow for effects of $T_{1}$ equilibrium. Whole brain coverage was achieved using 35 axial slices of $3 \mathrm{~mm}$ thickness with an inplane resolution of $3 \times 3 \mathrm{~mm}$ in a $64 \times 64$ voxel matrix (FOV $192 \mathrm{~mm}$ ). Images were obtained with a TR of $2200 \mathrm{~ms}$, a $30 \mathrm{~ms}$ TE and a $90^{\circ}$ flip angle. A high-resolution 3D GR $T_{1}$ anatomical scan was acquired for spatial processing of the fMRI data. It consisted of $256 \times 256 \times 134$ voxels with a $0.94 \times 0.94 \times 1.2 \mathrm{~mm}^{3}$ voxel size, obtained with a TR of $6.552 \mathrm{~ms}$, a $2.824 \mathrm{~ms}$ TE and a $14^{\circ}$ flip angle.

Cardiac responses and respiration data were sampled continuously during scanning at $1000 \mathrm{~Hz}$ using the scanner equipment. Time stamps for each heartbeat were automatically generated.

\subsection{Data preprocessing}

Data preprocessing and analysis was performed using Statistical Parametric Mapping software (SPM8; Wellcome Department of Imaging Neuroscience, www.fil.ion.ucl.ac.uk/spm), implemented in MatLab.

Functional images were motion corrected and registered to the first EPI image. The mean of the motion-corrected images was then coregistered to the individual's structural MRI using a nine-parameter affine transformation. The anatomical image was spatially normalized to the standard MNI space using the unified segmentation-normalization algorithm within SPM (Ashburner \& Friston, 2005) with the resulting deformation field subsequently applied to the fMRI data. Finally, data were spatially smoothed with an isotropic $8 \mathrm{~mm}$ full width at half maximum (FWHM) Gaussian kernel to account for differences between participants.

\subsection{Data analysis}

Statistical analysis was conducted using a two-level general linear model approach (Penny \& Holmes, 2007; Worsley \& Friston, 1995).

The regressor with onsets and durations for each motion verb clause was convolved with the standard HRF. Nuisance effects were factored out using a nuisance variable regression approach (Lund et al., 2006). This approach includes regressors based on cardiac and respiratory oscillations and six motion parameters in addition to the SPM8 standard discrete cosine set high-pass filter (128 s cut off). Sound intensity was modeled by taking the total power of the sound file frequency spectrum in time bins corresponding to each TR and convolving the resulting time series with the standard hemodynamic response function in SPM. We further added a regressor with the onsets for all words in the text, convolved with the standard HRF together with a parametric modulation of the log-frequency of all words (frequency defined within the text). Word co-occurrence effects (Wallentin et al., 2009; Wallentin, Vuust, Mouridsen, Roepstorff, \& Lund, 2009) were modeled by making onset regressors for all distinct words, convolved with the standard HRF. These regressors were then subjected to a principal component analysis and the 10 first components from this procedure were added to the set of regressors. Emotional effects were modeled using three regressors, an intensity regressor and two regressors modeling emotional valence (see Wallentin et al., submitted for publication). The motion verb regressor was orthogonalized to all of these regressors using the serial orthogonalization procedure in SPM. This means that only effects that could not be explained by any of the nuisance regressors should be picked up by the regressor of interest.

Group RFX analysis was conducted using a one-sample t-test on the single subject beta images from the motion verb regressor. Significance threshold was set to $P<0.05$ FWE-corrected for multiple comparisons.

\section{Acknowledgments}

This study was supported by The Carlsberg Foundation, The John \& Birthe Meyer foundation, The Danish National Research Foundation's Grant to CFIN, and the MindLab Grant from the Danish Ministry of Science, Technology and Innovation.

\section{References}

Anderson, J. M. (2007). Finiteness, mood, and morphosyntax. Journal of Linguistics, 43(1), 1-32.

Ashburner, J., \& Friston, K. J. (2005). Unified segmentation. Neuroimage, 26(3) 839-851.

Barsalou, L. W. (2008). Grounded cognition. Annual Review of Psychology, 59, 617-645.

Barsalou, L. W., Simmons, W. K., Barbey, A. K., \& Wilson, C. D. (2003). Grounding conceptual knowledge in modality-specific systems. Trends in Cognitive Sciences, 7(2), 84-91.

Bedny, M., Caramazza, A, Grossman, E., Pascual-Leone, A. \& Saxe, R. (2008) Concepts are more than percepts: The case of action verbs. Journal of Neuroscience, 28(44), 11347-11353.

Bremmer, F., Schlack, A., Shah, N. J., Zafiris, O., Kubischik, M., Hoffmann, K., et al. (2001). Polymodal motion processing in posterior parietal and premotor cortex: A human fMRI study strongly implies equivalencies between humans and monkeys. Neuron, 29(1), 287-296.

Brennan, J., Nir, Y., Hasson, U., Malach, R., Heeger, D. J., \& Pylkkänen, L. (in press) Syntactic structure building in the anterior temporal lobe during natural story listening. Brain and Language. doi:10.1016/j.band/2010.04.002.

Chatterjee, A. (2010). Disembodying cognition. Language and Cognition, 2(1) 79-116.

Crinion, J. T., Lambon-Ralph, M. A., Warburton, E. A., Howard, D., \& Wise, R. J. S. (2003). Temporal lobe regions engaged during normal speech comprehension. Brain, 126(Pt 5), 1193-1201.

Deen, B., \& McCarthy, G. (2010). Reading about the actions of others: Biological motion imagery and action congruency influence brain activity. Neuropsychologia, 48(6), 1607-1615.

Dumoulin, S. O., Bittar, R. G., Kabani, N. J., Baker, C. L., Le Goualher, G., Bruce Pike, G. et al. (2000). A new anatomical landmark for reliable identification of human area V5/MT: A quantitative analysis of sulcal patterning. Cerebral Cortex, 10(5), 454-463.

Hauk, O., Johnsrude, I., \& Pulvermüller, F. (2004). Somatotopic representation of action words in human motor and premotor cortex. Neuron, 41(2), 301-307.

Kable, J. W., Lease-Spellmeyer, J., \& Chatterjee, A. (2002). Neural substrates of action event knowledge. Journal of Cognitive Neuroscience, 14(5), 795-805.

Kemmerer, D. (2005). The spatial and temporal meanings of English prepositions can be independently impaired. Neuropsychologia, 43(5), 797-806.

Kemmerer, D. (2010). How words capture visual experience: The perspective from cognitive neuroscience. In B. Malt \& P. Wolff (Eds.), Words and the world: How words capture experience (pp. 289-330). Oxford: Oxford University Press.

Kemmerer, D., Castillo, J. G., Talavage, T., Patterson, S., \& Wiley, C. (2008) Neuroanatomical distribution of five semantic components of verbs: Evidence from fMRI. Brain and Language, 107(1), 16-43.

Kemmerer, D., Rudrauf, D., Manzel, K., \& Tranel, D. (in press). Behavioral patterns and lesion sites associated with impaired processing of lexical and conceptual knowledge of actions. Cortex. doi:10.1016/j.cortex.2010.11.001.

Kourtzi, Z., \& Kanwisher, N. (2000). Activation in human MT/MST by static images with implied motion. Journal of Cognitive Neuroscience, 12(1), 48-55.

Krumbholz, K., Schönwiesner, M., Rübsamen, R., Zilles, K., Fink, G. R., \& von Cramon, D. Y. (2005). Hierarchical processing of sound location and motion in the human brainstem and planum temporale. European Journal of Neuroscience, 21(1), 230-238.

Lund, T. E., Madsen, K. H., Sidaros, K., Luo, W.-L., \& Nichols, T. E. (2006). Non-white noise in fMRI: Does modelling have an impact? Neuroimage, 29(1), 54-66.

Meteyard, L., Bahrami, B., \& Vigliocco, G. (2007). Motion detection and motion verbs: Language affects low-level visual perception. Psychological Science, 18(11), 1007-1013.

Meteyard, L., Cuadrado, S. R., Bahrami, B., \& Vigliocco, G. (2010). Coming of age: A review of embodiment and the neuroscience of semantics. Cortex. 
Noppeney, U., Josephs, O., Kiebel, S., Friston, K. J., \& Price, C. J. (2005). Action selectivity in parietal and temporal cortex. Cognitive Brain Research, 25(3), 641-649.

Oldfield, R. C. (1971). The assessment and analysis of handedness: The Edinburgh inventory. Neuropsychologia, 9(1), 97-113.

Penny, W., \& Holmes, A. P. (2007). Random effects analysis. In K. J. Friston, J. Ashburner, S. Kiebel, T. Nichols, \& W. Penny (Eds.), Statistical parametric mapping: The analysis of functional brain images (pp. 156-165). London: Academic Press.

Phillips, J. A., Noppeney, U., Humphreys, G. W., \& Price, C. J. (2002). Can segregation within the semantic system account for category-specific deficits? Brain, 125(9), 2067-2080.

Pulvermüller, F. (2005). Brain mechanisms linking language and action. Nature Reviews. Neuroscience, 6(7), 576-582.

Revill, K. P., Aslin, R. N., Tanenhaus, M. K., \& Bavelier, D. (2008). Neural correlates of partial lexical activation. Proceedings of the National Academy of Science USA, 105(35), 13111-13115.

Richardson, D., \& Matlock, T. (2007). The integration of figurative language and static depictions: An eye movement study of fictive motion. Cognition, 102(1), $129-138$.

Roepstorff, A., \& Frith, C. (2004). What?s at the top in the top-down control of action? Script-sharing and? top-top? control of action in cognitive experiments. Psychological Research, 68(2-3), 189-198.

Ruby, P., \& Decety, J. (2001). Effect of subjective perspective taking during simulation of action: A PET investigation of agency. Nature Neuroscience, 4(5), 546-550.

Rueschemeyer, S.-A., Glenberg, A. M., Kaschak, M. P., Mueller, K., \& Friederici, A. D. (2010). Top-down and bottom-up contributions to understanding sentences describing objects in motion. Frontiers in Psychology, 1, 1-11.

Small, S. L., \& Nusbaum, H. C. (2004). On the neurobiological investigation of language understanding in context. Brain and Language, 89(2), 300-311.

Smith, K. R., Saberi, K., \& Hickok, G. (2007). An event-related fMRI study of auditory motion perception: No evidence for a specialized cortical system. Brain Research, 1150, 94-99.

Speer, N. K., Reynolds, J. R., Swallow, K. M., \& Zacks, J. M. (2009). Reading stories activates neural representations of visual and motor experiences. Psychological Science, 20(8), 989-999.

Speer, N. K., Zacks, J. M., \& Reynolds, J. R. (2007). Human brain activity time-locked to narrative event boundaries. Psychological Science, 18(5), 449-455.

Talmy, L. (2000). Toward a cognitive semantics. Cambridge, Mass: MIT Press.

Thompson-Schill, S. L. (2003). Neuroimaging studies of semantic memory: Inferring "how" from "where". Neuropsychologia, 41(3), 280-292.

Tylén, K., Weed, E., Wallentin, M., Roepstorff, A., \& Frith, C. D. (2010). Language as a tool for interacting minds. Mind and Language, 25(1), 3-29.
Wallentin, M. (2009). Putative sex differences in verbal abilities and language cortex: A critical review. Brain and Language, 108(3), 175-183.

Wallentin, M., Lund, T., Østergaard, S., Østergaard, L., \& Roepstorff, A. (2005). Motion verb sentences activate left posterior middle temporal cortex despite static context. Neuroreport, 16(6), 649.

Wallentin, M., Nielsen, A. H., Vuust, P., Dohn, A., Roepstorff, A., \& Lund, T. E. (submitted for publication) Amygdala and heart rate variability responses from listening to emotionally intense parts of a story. Neuroimage.

Wallentin, M., Vuust, P., Mouridsen, K., Dohn, A., Nielsen, A. H., Roepstorff, A., et al. (2009). Word co-occurrence effects driving language cortex during listening to a narrative. Neuroimage, 47(Suppl. 1), S165.

Wallentin, M., Vuust, P., Mouridsen, K., Roepstorff, A., \& Lund, T. E. (2009). Covariance structures in narratives studied with fMRI - Proof of concept, CNS 2009 - The 16th annual meeting of the cognitive neuroscience society. San Francisco.

Wallentin, M., Weed, E., Østergaard, L., Mouridsen, K., \& Roepstorff, A. (2008). Accessing the mental space-spatial working memory processes for language and vision overlap in precuneus. Human Brain Mapping, 29(5), 524-532.

Wallentin, M., Østergaard, S., Lund, T. E., Østergaard, L., \& Roepstorff, A. (2005). Concrete spatial language: See what I mean? Brain and Language, 92(3), 221-233.

Warren, J. D., Zielinski, B. A., Green, G. G. R., Rauschecker, J. P., \& Griffiths, T. D. (2002). Perception of sound-source motion by the human brain. Neuron, 34(1), 139-148.

Wilson, S. M., Molnar-Szakacs, I., \& Iacoboni, M. (2007). Beyond superior temporal cortex: Intersubject correlations in narrative speech comprehension. Cerebral Cortex, 18(1), 230-242.

Worsley, K. J., \& Friston, K. J. (1995). Analysis of fMRI time-series revisited - Again. Neuroimage, 2(3), 173-181.

Xu, J., Kemeny, S., Park, G., Frattali, C., \& Braun, A. (2005). Language in context: Emergent features of word, sentence, and narrative comprehension. Neuroimage, 25(3), 1002-1015.

Yarkoni, T., Speer, N. K., \& Zacks, J. M. (2008). Neural substrates of narrative comprehension and memory. Neuroimage, 41(4), 1408-1425.

Zacks, J. M., Speer, N. K., \& Reynolds, J. R. (2009). Segmentation in reading and film comprehension. Journal of Experimental Psychology General, 138(2), 307-327.

Zeki, S., Watson, J. D., Lueck, C. J., Friston, K. J., Kennard, C., \& Frackowiak, R. S. (1991). A direct demonstration of functional specialization in human visual cortex. Journal of Neuroscience, 11(3), 641-649.

Zwaan, R. A., Madden, C. J., Yaxley, R., \& Aveyard, M. E. (2004). Moving words: Dynamic representations in language comprehension. Cognitive Science, 28, 611-619.

Zwaan, R. A., Stanfield, R. A., \& Yaxley, R. H. (2002). Language comprehenders mentally represent the shapes of objects. Psychological Science, 13(2), 168-171. 